\title{
Controversial treatments in psychiatry
}

\section{Jason Luty}

\begin{abstract}
SUMMARY
Psychiatry uses some of the most controversial treatments in medicine. This may be partly because several are administered under coercion and opposed to the patient's expressed will, under the protection of the relevant mental health legislation. Electroconvulsive therapy (ECT) is perhaps the archetypal controversial treatment; although it is considered to be effective, the research supporting it is much less impressive than one would expect. The prescription of stimulant drugs for childhood attention-deficit hyperactivity disorder (ADHD) and substitution therapy (such as methadone maintenance) in addictions treatment remain topical and appear to be subject to political interference. 'Treatment' for homosexuality and psychosurgery were common in the past but are now rare. These issues are discussed to give insight into how once common controversial treatments can decline and become obsolete. However, seclusion and covert medication remain in practice and are highly scrutinised.
\end{abstract}

\section{LEARNING OBJECTIVES}

- Recognise that many controversial treatments, such as psychosurgery, have been superseded by psychotropic drugs used since the 1950s

- Be aware of the limitations of evidence supporting controversial treatments, such as stimulants for childhood ADHD and ECT for depression in adults

- Be aware that controversial treatments are highly emotive and may be viewed negatively by the public or politicians, despite evidence for their safety and effectiveness

\section{DECLARATION OF INTEREST}

None

\section{Electroconvulsive therapy}

There are few treatments as controversial as electroconvulsive therapy (ECT). The US author Ernest Hemingway died by suicide shortly after undergoing ECT at the Mayo Clinic in 1961, reportedly saying about ECT 'What is the sense of ruining my head and erasing my memory?'. ECT was graphically described by Ken Kesey, who had worked as an orderly at a mental health facility in California, in One Flew Over the Cuckoo's Nest.

Seizures have been used to treat mental health problems ('hysteria') since the mid-1700s. In 1934, the Hungarian psychiatrist Ladislas Meduna used camphor-induced seizures as a treatment, on the basis of the incorrect theory that epilepsy and schizophrenia could not exist together. Electrically induced seizures were developed by Italian psychiatrists Ugo Cerletti and Lucio Bini in 1938. This followed Cerletti observing seizures in pigs who were given an electric shock as an anaesthetic before being slaughtered. ECT was effective in depression and catatonic schizophrenia. In the 1940s, ECT was usually given in 'unmodified' form, without muscle relaxants. Muscle relaxants (curare and suxamethonium) were introduced later, along with general anaesthesia to reduce the risk of fractures during seizures. ECT became less popular with the arrival of modern antidepressants in the 1950s. In the UK, an estimated 12000 people received ECT in 1980 (Department of Health 2003), although the prevalence had fallen to around 400 patients by 2013 (Reed 2013). ECT is typically given twice a week for 6-12 weeks. In the past, women were at least twice as likely to receive ECT as men. This has raised concerns about gender bias as, until recently, psychiatrists were usually men.

ECT is now used to treat very severe psychiatric disorders which are often life threatening, where a rapid response is required. These include severe depression, resistant mania or catatonia (National Institute for Health and Care Excellence (NICE) 2003). To give an illustration of the risk and benefits, it is estimated that $15 \%$ of people with severe depression will die by suicide.

NICE (2003) refers to a report containing 90 randomised controlled trials of ECT in depression and 25 trials in schizophrenia. Many of the trials were performed prior to the 1980s, when ECT was not used in the same manner or for the same indications as in current practice. For example, one study from 1959 involved patients who did not know they were being included in a trial. Many of the older studies had fewer than 10 participants. Overall, the trials suggest that ECT has the advantage of rapid response but is no more effective than antipsychotics in schizophrenia.

Several studies have compared the effect of ECT with placebo - that is, using a brief general anaesthetic without inducing a seizure using an electric current ('sham ECT'). The UK ECT Review Group (2003) and NICE (2009) analysed results from 31 randomised trials including over 1600 participants. They reported an effect size of 0.230 0.322 (by convention, this is considered a small-tomedium effect size). This provides some evidence
Jason Luty is a consultant in addictions psychiatry at Borders Health. He has published in the addictions field, trained at the Maudsley Hospital, London, and spent 8 years as consultant in addictions at the South Essex Partnership NHS Trust. Correspondence Dr Jason Luty, Borders Addiction Service, The Range, Tweed Road, Galashiels TD1 3EB, UK. Email: jason.luty@ yahoo.co.uk

Copyright and usage (C) The Royal College of Psychiatrists 2017. 
that ECT is superior to sham ECT (anaesthesia alone), although the placebo response is remarkably high (Rasmussen 2009).

Perhaps the best known trial is the Northwick Park study of ECT (Clinical Research Centre 1984) involving 70 patients. The results were presented graphically. There was a reduction from baseline scores of 50-55 on the Hamilton Rating Scale for Depression to an average score of around 15 in the ECT group and 25 in the sham ECT group. The proportion of patients showing clinically significant improvement (halving of the Hamilton score) was probably very close between the ECT and sham ECT groups. By contrast, the Nottingham ECT study (Gregory 1985) involved 3 groups of 26 patients (total 78) receiving bilateral, unilateral and sham ECT. There was a baseline mean Montgomery-Åsberg Depression Rating Scale score of approximately 34, falling to 10 in both the ECT treatment groups but 24 in the sham group. This was a highly significant outcome.

The effect size of $0.2-0.3$ reported by the meta-analysis of sham ECT is surprisingly small. Similarly, the large and often quoted Northwick Park study found a significant improvement in the response of the control group, with the proportion of participants reporting clinically (rather than statistically) significant difference being probably very close (the results are portrayed graphically, which hampers further scrutiny). Consequently, much of the scientific support for ECT is based on the Nottingham trial. Considering the highly controversial nature of ECT, this paucity of evidence is surprising. Moreover, there is far more evidence to support other controversial treatments such as stimulant use in children (possibly because this research was funded by pharmaceutical companies).

Some researchers have analysed the work that has been done on patients' experiences of ECT. They reported that the proportion of people who had had ECT and found it helpful ranged from 30\% to $80 \%$. However, the researchers noted that studies reporting lower satisfaction tended to have been conducted by patients, and those reporting higher satisfaction were carried out by doctors. Between 30 and $50 \%$ of patients complained of memory problems after ECT (Rose 2003).

Common side-effects of ECT include brief memory loss and confusion, and minor injuries (such as damage to dental work). There are also the risks associated with general anaesthesia. Less common complications include status epilepticus, laryngospasm and peripheral nerve palsy (incidence of less than 1 in 1000 treatments) (NICE 2003).

Surveys conducted by doctors have reported a low level of severe side-effects (such as long-term memory problems). However, surveys conducted by patients report that up to half of those who have had ECT complain of significant memory problems (Rose 2003). NICE (2003) concluded that 'There is clear evidence that cognitive impairment occurs both immediately after administration of ECT and following a course of therapy', although it is uncertain whether memory loss exceeds 6 months. Short-term amnesia occurs in many mental health problems, particularly following acute episodes (Ingram 2008). Hence, it is difficult to determine whether amnesia is due to ECT or to the severe mental illness that ECT was being used to treat.

A particular issue for patients is the report that ECT may cause more profound memory problems, specifically amnesia for autobiographical events such as memories of childhood (Lisanby 2000; Rose 2003; Ingram 2008). This is rather challenging to neuroscientists, as most other physical traumas, such as serious head injuries, do not cause specific autobiographical amnesia, at least not without obvious damage to global brain functions like speech and movement. Although many expert groups are probably reluctant to enunciate this, some patient accounts raise the possibility of suggestibility and dissociative disorders that could explain some of reported autobiographical memory problems. In other words, these are subconscious memory problems rather than a result of neurological damage. This is a particular possibility for patients with emotionally unstable personality disorders - a group who are also highly vocal and particularly prone to dissociative disorders. Rose et al (2003) summarised the results of 7 studies reporting on perceived memory loss and found that between 29 and $55 \%$ of respondents believed they experienced long-lasting or permanent memory changes. This issue remains unresolved.

The Royal College of Psychiatrists'ECT Accreditation Service (ECTAS) provides independent assessment of the quality of ECT services. ECTAS sets very high standards and visits all the units registered with it - currently over $78 \%$ of ECT clinics in England and Wales, plus a number in Northern Ireland and the Republic of Ireland (www.rcpsych. ac.uk/workinpsychiatry/qualityimprovement/ ccqiprojects/ectclinics/ectas.aspx).

\section{Psychosurgery}

Psychosurgery is performed to treat severe incapacitating mental disorders, usually severe depression or obsessive-compulsive disorder (OCD), when medication and ECT have failed. Psychosurgery is now very rarely performed. For example, in 2013 and 2014 there were only 4 or 5 such operations in the UK. However, in the 1940s, prior to modern psychotropic drugs, psychosurgery 
became commonplace, including the so-called 'frontal lobotomy' vilified in the film One Flew Over the Cuckoo's Nest (Crossley 1993; Berrios 1997; Mashour 2005).

Modern psychosurgery involves the use of small bore-holes in the forehead rather than opening the skull (craniotomy) (Mind 2015). Needles are then inserted very accurately via a stereotactic frame to destroy parts of the caudate nucleus (subcaudate tractotomy), the adjoining internal capsule (bilateral anterior capsulotomy) or the anterior cingulate gyrus (bilateral anterior cingulotomy). An even more updated procedure, deep brain stimulation (DBS), involves inserting electrodes to stimulate various brain areas rather than destroying them. The operation usually takes about 90 minutes. Patients will usually be mobile within 3 days. The main side-effects are headache and apathy (lack of drive and motivation). Of course, the obsolete lobotomies could produce severe apathy and were widely condemned for this. Recovery from the mental disorder (usually severe depression) is not immediate and takes several months.

In the UK, psychosurgery requires valid consent from the patient and a second opinion - usually from experts appointed by a statutory body, such as the Mental Welfare Commission for Scotland, or a second opinion doctor appointed for the purpose. Patients are typically so disabled that they have spent long periods in hospital prior to being assessed for psychosurgery.

DBS and vagus nerve stimulation (VNS) are reversible alternatives to psychosurgery - no brain tissue is deliberately destroyed. As these techniques improve, they are likely to replace psychosurgery.

Success rates for modern psychosurgery in treating depression and OCD have been reported as between 25 and 70\% (Mashour 2005). However, the quality of outcome data is poor and reviewers, including expert groups from the Royal College of Psychiatrists, indicated that it was not possible to confirm the effectiveness of modern psychosurgery (Royal College of Psychiatrists 2000; Matthews 2003). Problems for appraisers of psychosurgery include the small numbers treated at any one centre, positive publication bias and the inability to use a comparable control group. Controlled studies are very rare, and there have been no placebocontrolled studies.

The Portuguese neurologist Egas Moniz developed the frontal lobotomy in the 1930s (Moniz received the Nobel prize for this work in 1949). Moniz devised the theory that people with mental illnesses had a defect in neuronal connections which allowed unhealthy ideas to circulate continuously in their brains. The frontal lobotomy was promoted in the USA by the psychiatrist Walter
Freeman and the neurosurgeon James W. Watts, who devised the standard prefrontal lobotomy (cutting of the (frontal) lobe) (Bridges 1994). The operation was called 'leucotomy' in the UK. The lobotomy involved cutting the connections between the prefrontal lobes and deeper structures using a burr hole on either side of the skull. Freeman then developed the transorbital or 'ice pick' lobotomy, which could be conducted under local anaesthesia or during ECT. This could be performed in mental hospitals which lacked surgical facilities. Freeman travelled around the USA in his own personal van, the 'lobotomobile', conducting the procedure in psychiatric hospitals. Freeman's patients included 19 children, one of whom was 4 years old (Swayze 1995; Lewis 2005).

There was a rapid expansion of psychosurgery in the USA in the 1940s, although lobotomy involved a $6 \%$ risk of death and also severe personality changes. Up to 5000 psychosurgical operations were being carried out each year in the USA by 1950 (Swayze 1995). During the 1960s and 1970s, psychosurgery became the subject of increasing public concern and debate, whereas psychotropic drugs provided a much less controversial alternative. Psychosurgery was regulated in the 1970s in the USA following congressional hearings and inquiries into the work of Harvard neurosurgeon Vernon Mark and psychiatrist Frank Ervin (Mashour 2005). In these cases, amygdalotomies had been performed to reduce 'pathologic aggression' in patients with temporal lobe seizures (Heller 2006).

The first British lobotomy operation was performed in Bristol in December 1940. By 1954, around 12000 psychosurgical operations had been performed, although the number halved during the 1950s, with the introduction of psychotropic drugs (Barraclough 1978; Bridges 1994; Mental Health Act Commission 2008). As with ECT, women have outnumbered men (Crossley 1993). This has raised concerns, particularly among feminists, because the situation often involved men (male psychiatrists) giving a highly controversial treatment to women. This was particularly sensitive as the treatment could be perceived as punishment.

In 1949, Geoffrey Knight, working at Runwell Hospital in Essex, started performing the operation of orbital undercutting (called 'orbital leucotomy' in the UK). This involved cutting the lower medial quadrants of the frontal lobes. The procedure was modified in 1961 to use a stereotactic frame. Knight later operated at the Brook Hospital in South London, where nearly 1300 subcaudate tractotomies, 'Knight's operation', were performed. Around $75 \%$ of all psychosurgical operations in the UK were performed at Brook Hospital in the 1980s (Bridges 1994). 


\section{Stimulants for attention-deficit hyperactivity disorder}

In 1937, Charles Bradley in New York reported that a group of children with behavioural problems showed some improvement after being treated with benzedrine. Methylphenidate (most commonly known under the trade name Ritalin ${ }^{\oplus}$ ) was synthesised in 1944 and began to be used for childhood problems in 1954. The drug was originally developed to treat narcolepsy, chronic fatigue and depression (Strohl 2011).

Childhood attention-deficit hyperactivity disorder (ADHD) is the second most common mental disorder of children and is characterised by inattention, hyperactivity and impulsivity which disrupt learning and social functioning. Methylphenidate remains the mainstay of treatment for childhood ADHD (King 2006; NICE 2008). The overall effect size for methylphenidate is estimated at 1.0 (Pliszka 2007) and that for atomoxetine at 0.7 (Michelson 2002). Other studies report a number needed to treat of 3 for methylphenidate and 5 for atomoxetine (Banaschewski 2006). However, no major follow-up studies show any benefit of medication in the long term (Riddle 2013).

By contrast, the evidence base, especially randomised controlled trials, is weak for many psychosocial interventions for ADHD. These interventions include parent training, social skills training, cognitive training or classroom interventions (Sonuga-Barke 2013; Verkuijl 2015). For example, a review in 2010 found no studies reporting that cognitive-behavioural therapy was effective for childhood ADHD (Young 2010).

The Multimodal Treatment Study of 436 children with $\mathrm{ADHD}$ is the largest randomised clinical trial to date (Molina 2009). After 14 months of treatment, the groups receiving stimulant medication and stimulant medication plus behavioural therapy had both improved significantly, but the addition of the behavioural intervention had not yielded significantly greater benefits. Unfortunately, the benefits had been lost by follow-up at 8 years.

Prevalence rates of childhood ADHD vary greatly between different countries, according to social customs, diagnostic criteria and whether the diagnosis is made by specialists or primary care physicians. A worldwide prevalence of around $2.2 \%$ in boys and $0.7 \%$ in girls is reported (NICE 2008). Unusually high rates of childhood ADHD have been reported in the USA, where high rates of stimulant medication are prescribed (Moncrieff 2013). It has been suggested that financial vested interests, particularly from the manufacturers of methylphenidate, have influenced the diagnostic criteria, making these over-inclusive. Furthermore, many researchers and websites about ADHD are financially supported by the pharmaceutical industry (Monynihan 2011; Moncrieff 2013).

Two highly publicised studies examined parent ratings for a diagnosis of childhood ADHD. A US study reported a $42 \%$ increase in ADHD diagnoses from 2003 to 2011, ultimately suggesting that up to $8.8 \%$ of the children had a diagnosis of $\mathrm{ADHD}$ (Visser 2014). By contrast, a UK study reported a prevalence of only $1.7 \%$, with no evidence of an increase between 1999 and 2009 (Russell 2014). Overall, $6.1 \%$ of children in the USA receive drugs for $\mathrm{ADHD}$, in contrast to an estimated $0.8 \%$ in the UK (McCarthy 2012).

The US Great Smoky Mountain longitudinal study of 4500 children suggested that only 3.4\% could be diagnosed with ADHD when parent and teacher ratings were included, although $7.3 \%$ were prescribed stimulant drugs (Angold 2000). The rate of stimulant prescription among children from wealthier backgrounds was twice that among poorer children, suggesting that more liberal prescribing in private practice was responsible for the difference. In addition, in the USA stimulants for ADHD are widely advertised directly to patients.

In 2008, US Senator Chuck Grassley undertook a congressional investigation that found that three international experts who had promoted psychoactive drugs (such as methylphenidate), Joseph Biederman, Timothy Wilens and Thomas Spencer, had violated federal regulations by failing to declare large sums of money they received from the companies which made the drugs (Kaplan 2011). In 2007, Biederman was ranked as the second highest producer of high-impact papers in psychiatry worldwide, with 235 papers.

There has been controversy in the UK too, as the recent NICE guidelines suggest that methylphenidate be used as first-line treatment only in severe childhood ADHD - a condition estimated to have a prevalence of 1\% (NICE 2016). Mild and moderate ADHD (UK prevalence 8\%) should be addressed initially with psychosocial methods, with drug treatment reserved for second-line treatment. This followed a 6-year period from 2007 to 2013 during which the number of methylphenidate prescriptions increased by 56\% (NICE 2008). Clearly, it is difficult to define the distinction between 'moderate' and 'severe' ADHD. However, the increased cost to the taxpayer of higher prescribing rates might be a politically motivated incentive to discourage the use of methylphenidate in childhood ADHD.

\section{Treatment of substance misuse}

It has been estimated that in the USA, $\$ 1$ spent on treatment for opiate dependence generates a 
total cost saving of $\$ 12$ in terms of health, reduced acquisitive crime and criminal justice costs. Similar estimates have been produced in the UK. Needle exchange programmes are among the most effective measures for preventing HIV transmission in highincome countries ( $\$ 1$ spent on needle exchanges will save $\$ 4$ in healthcare costs over 10 years and $\$ 27$ when lost productivity is taken into account) (Wodak 2004; National Centre in HIV Epidemiology and Clinical Research 2009).

By contrast, increased investment in drug treatment in England resulted in the number of people in contact with structured drug treatment agencies more than doubling, from 85000 in 1998 to 181000 in 2006, although this primarily involved people with heroin addiction (National Treatment Agency for Substance Misuse 2012).

In autumn 2009, Professor David Nutt publicly stated (more or less) that alcohol and tobacco were just as damaging to health as cannabis. Although he told the truth, he was immediately dismissed as head of the UK Advisory Committee on Substance Misuse (BBC 2009). This illustrates the politicised nature of substance misuse and how (misinformed) public opinion trumps scientific evidence.

\section{Abstinence v. maintenance}

In 2010, the new UK government announced that substance misuse treatment should follow a 'recovery agenda' - patients should aim for abstinence from all drugs (including prescribed medication) as soon as possible (HM Government Drug Strategy 2010). However, virtually all the evidence shows that abstinence-based treatment is far less effective than maintenance, in which patients remain on methadone (or buprenorphine) for a period of years (National Consensus Development Panel 1998; Sees 2000; Amato 2013). Indeed, a report from British Columbia of over 25000 methadone treatment episodes showed that only 1 in 40 achieved a successful 'recovery' (abstinence from prescribed methadone with no treatment re-entry within 18 months; Nosyk 2012). There are multiple comparable research reports (e.g. Amato 2011, 2013). By contrast, around half of patients who are maintained on methadone can almost completely abstain from heroin (Simpson 1997; Ward 1999; Gossop 2003). Despite the overwhelming evidence to the contrary, various governments, including the UK's, still endorse recovery-focused approaches, specifically abstinence-based treatments, over maintenance treatment for opiate addiction.

\section{Contingency management}

This involves rewarding positive behaviour. However, other more controversial techniques involve financial rewards, or entry into a lottery for prizes, for drug-free tests. The original studies of contingency management involved relatively high financial rewards (e.g. $\$ 1000$ for sustained abstinence from cocaine; Higgins 2000). More recent techniques involve much lower rewards (up to $\$ 100 ;$ Petry 2002). In 2007, NICE released guidelines encouraging modest prizes and financial rewards to encourage drug-users to abstain. Although the evidence for this is clear, political opposition in newspapers and political pressure has meant that contingency management is often ignored. Ultimately, using taxpayers' money to pay people to do what is in their own best interests is difficult to defend politically (Kendall 2013).

\section{Drug treatment and testing orders}

Drug treatment and testing orders (DTTOs) were introduced by the Crime and Disorder Act 1998 in the UK. They enabled the courts to order offenders to enter treatment or face alternative punishment (usually imprisonment) for their crime. The early pilots were 'hardly [...] unequivocally successful' (Turnbull 2000: p. 87), but they were introduced nationally regardless. The DTTO was replaced in England in 2005 by the similar Drug Rehabilitation Requirement (DRR).

The 2-year evaluation of DTTOs was based on 3 pilot sites that showed overall 2-year reconviction rates of $80 \%$ for 174 DTTO offenders. Completion rates for DTTOs were low: only 30\% finished their orders successfully, while $67 \%$ had their orders revoked. These results are very disappointing, and reconviction rates were broadly similar to those of other offenders who were not on DTTOs (Hough 2003). This is an excellent example of political enthusiasm overriding scientific scrutiny.

\section{Injectable opioid therapy}

The prescription of heroin to addicts as a substitution treatment certainly reduces offending in countries where it can legally be prescribed for addiction (Strang 2010). However, experience in the UK and The Netherlands shows that this expensive and controversial treatment is only likely to be available to a small proportion of opiate addicts (Strang 2010). Asking the taxpayer to fund $£ 18000$ per patient per annum (Byford 2013) to provide heroin for addicts to inject is an extremely unfavourable proposition - especially if the expenditure comes from the health budget while the savings accrue to the criminal justice system and to society in general. Unfortunately, similar arguments also apply to supervised injecting rooms, which are unlikely to be expanded owing to their cost and to political opposition. 


\section{Drug consumption rooms}

Drug consumption rooms provide relatively safe places to use drugs under medical supervision. They are associated with reductions in overdoses and in risky injection practices (Independent Working Group on Drug Consumption Rooms 2006). They also allow treatment services to engage with injecting drug users. However, in 2002, the UK government rejected a parliamentary committee's recommendation that safe injecting areas should be created (Home Affairs Select Committee 2002). The grounds for this decision were subsequently considered and dismissed by a government independent working group (Wright 2004). Despite this, drug consumption rooms (like injectable opioid therapy) are unlikely to be expanded.

\section{In summary}

There is overwhelming evidence for the benefits of maintenance rather than abstinence-based prescriptions in opioid dependence. However, methadone maintenance remains politically controversial, especially following increased rates of death from diverted methadone, which have exceeded death rates from heroin in some regions (National Records of Scotland 2016). There is also political opposition to the adoption of injectable opioid therapy, safe injecting rooms and contingency management. By contrast, political enthusiasm for DTTOs led to widespread adoption of these orders despite equivocal evidence for their effectiveness. It is salutary to note that a 1-year DTTO is perhaps 7 times cheaper than a 12-month prison sentence (roughly £5000 v. £37 000) (Home Office 2003; National Audit Office 2004).

\section{Psychiatry and homosexuality}

Homosexual acts, especially anal intercourse, have been criminalised since biblical times (Sodom and Gomorrah; Leviticus 20:13). Most homosexual activities have been condemned in Western society at some time or another, often on pain of death. In the 19th century, doctors began to suggest that homosexuality was a mental illness and that homosexuals should receive psychiatric care rather than face draconian punishment. The German-Austrian psychiatrist Richard Krafft-Ebing was an influential proponent of the disease model of homosexuality (Krafft-Ebing 1886). Although this medicalisation could seem prejudiced today, it may actually have been rather enlightened by comparison with the views of his contemporaries. The term 'homosexual' was first used in 1869 as part of a campaign against German homosexuality laws.

By the 20th century, the medicalisation of homosexuality was being abused. Until the 1970s, homosexuality was considered a mental illness and homosexuals were coerced into a variety of treatments (some now considered to be not only ineffective but inhumane). Homosexuality was removed from the American Psychiatric Association's Diagnostic Classification Manual in 1973 following the Stonewall riots and civil rights movements of the late 1960s. Hence, homosexuality is now regarded as a normal sexual variation rather than a disorder.

Virtually every psychiatric technique has been used to 'treat' homosexuality in the past, including ECT, surgery (hysterectomy, ovariectomy, clitoridectomy, castration, vasectomy, pudic nerve surgery and lobotomy) and hormonal treatment (Yoshino 2002). Treatment for homosexuality began as early as the 1860s, when Krafft-Ebing proposed measures such as prevention of masturbation and hypnosis. While he recognised that the results of these treatments were poor, he opposed the detention of people in asylums for being homosexual. Around the same time, Eugen Steinach, a Viennese endocrinologist, was transplanting testes from heterosexual men into homosexual men as a treatment for homosexuality.

Aversion therapy for homosexuality became popular in the 1960s. It involves pairing of homoerotic images with unpleasant stimuli such as electric shocks to the genitals and emetic drugs that cause vomiting. Heterosexual imagery is then paired with pleasant stimuli. Aversion therapy claimed a $50 \%$ success rate, although enthusiasm for these methods waned when the trials were discovered to be scientifically flawed. Many commentators regard aversion therapy as a form of torture. Much 'mainstream' treatment for homosexuality involved traditional psychotherapy. Although this was far more humane than many behavioural or surgical interventions, its effectiveness is highly questionable.

An example of more traditional psychotherapy includes Joseph Nicolosi's reparative therapy, which encourages patients to participate in sports, avoid activities considered of interest to homosexuals (such as art galleries and opera), avoid women unless it is for romantic contact, increase time spent with heterosexual men, join a men's church group, date women, engage in heterosexual intercourse and, more dramatically, enter into heterosexual marriage and father children.

Marriage therapy and relationship counselling have been advocated for homosexual and bisexual people in opposite-sex marriages. Groups such as Exodus International provide religious-based therapy such as prayer groups and residential placements for homosexual people.

Less cavalier methods are still employed by some therapists today and include hypnosis, behavioural, cognitive-behavioural and psychoanalytic 
techniques, and religious and spiritual approaches. There remains no convincing evidence of effectiveness. For example, in 2001 the United States Surgeon General stated that 'there is no valid scientific evidence that sexual orientation can be changed' (Satcher 2001).

The National Association for Research and Therapy of Homosexuality (NARTH) in the USA offers conversion (also known as reparative or reorientation) therapy for homosexuality. Conversion therapy is highly controversial and includes aversion therapy, masturbatory reconditioning, visualisation, social skills training, psychoanalytic therapy and spiritual interventions such as 'prayer, group support and pressure' (Haldeman 1991). Conversion therapy was popular in the 1930s to the late 1960s, but it was gradually disowned by the medical establishment, which developed the view that homosexuality was a normal variant. There was also concern that it was ineffective and often distressing, and that some patients, especially young people, were coerced into treatment by their peers. In 2006, a survey of members of the American Psychiatric Association stated that conversion therapy was 'certainly discredited' (Norcross 2006).

'Treatment' for homosexuality is now discouraged by most mainstream groups, such as the American Psychiatric Association. Nevertheless, a small number of people do present for treatment, particularly people with strong religious convictions. The view that homosexuality is treatable is still propounded by groups such as the Catholic Medical Association and other strongly religious or rightwing groups. A small minority of British and American psychotherapists still offer treatment.

\section{Seclusion}

The Mental Welfare Commission for Scotland (2014) states that 'Locking someone in a room alone [without their consent as an emergency measure], because of their behaviour, is usually referred to as seclusion'. It goes on to say that seclusion 'should not be regarded as a therapeutic intervention but it may be necessary as an alternative for managing extremely difficult situations', primarily to protect others from harm, especially where staff have already been injured. The sole justification for seclusion is therefore to contain severely disturbed behaviour which is likely to cause harm to others. Seclusion should not be used as a punishment or a threat, as part of a treatment programme, because of a shortage of staff or where there is a risk of suicide or self-harm (Department of Health 2015).

A ruling from the House of Lords states that seclusion (Box 1) is justifiable if there is a threat to public safety, to prevent disorder or crime, to protect 'health and morals', and to protect rights

and freedom of others, although this judgement is rather over-inclusive and would also apply to many forms of coerced treatment and lawful imprisonment (Johnstone 2005; Department of Health 2015).

In a literature review on seclusion, Van der Merwe et al (2009) noted that, according to annual censuses in England and Wales from 2005 to 2008, $3-4 \%$ of in-patients in mental health facilities had experienced one or more episodes of seclusion, and $8-12 \%$ had experienced at least one episode of manual restraint during their stay.

Despite the large number of papers on the subject of seclusion, the review found no randomised controlled trials. More than half of the studies $(n=75)$ identified were conducted in an acute or psychiatric intensive care setting, with 25 in forensic settings. Seclusion rates vary internationally, with averages ranging from 11 to 28 per 100 admissions per month. Duration of seclusion also varies internationally, from an average of 3 to 55 hours per month. The four most prevalent reasons for patients being secluded involved aggression in one form or another. Of 47 studies, 28 stated that physical aggression towards objects was the main reason for seclusion, 23 gave verbal aggression as the reason, 22 reported that patients were secluded

\section{BOX 1 Design of seclusion rooms}

'[Seclusion rooms] must be large enough to accommodate the individual and the maximum number of staff who may be involved in any restraint procedures. The construction of walls, windows, doors, hinges and locks must be robust enough to withstand high levels of violence aimed at damaging the physical environment. There must be no ligature points or access to electrical fixtures and fittings that pose a risk of shock. There must be no opportunity to barricade the door to prevent entry. Furnishings must be comfortable but safe and robust and not be of use as a weapon. Observation into the room should be clear and effective. It should not be possible for onlookers to view into the room from the outside.'

'The room [...] should be decorated in a calming manner. [...] Bedding must be as safe as possible. Clothing should be risk assessed prior to seclusion to ensure that any potentially dangerous items are removed. [...] The principle of least restriction should be applied to the removal of items. Nothing should be removed unless there is clear justification on the basis of risk of harm to the person or to others.
Personal items of religious or cultural significance should remain unless these may compromise safety.

'[Following seclusion the on-call doctor and a] senior member of nursing staff must be notified, and should visit as soon as practicable [the senior doctor should be informed, or visit the unit, as soon as practical thereafter]. [...] Should the seclusion continue beyond 30 minutes, plans for meeting the individual's need for eating, drinking and toileting should be clearly recorded. [...] Care staff allocated to the individual must remain within sight and sound of the seclusion room at all times during the period of seclusion either directly through observation or via CCTV. [...] Seclusion must not go on for any longer than is absolutely necessary [...] a written record should be made at least every 15 minutes [and the seclusion should be reviewed every 12 hours by a senior doctor or manager. Episodes of seclusion should be reported to the relevant statutory body]. A member of care staff must be in attendance immediately outside a seclusion room at all times.'

(Mental Welfare Commission for Scotland 2014) 
because of aggression directed at themselves, and in 20 seclusion was because of physical aggression to others. The fifth most prevalent reason for seclusion was that the patient was refusing to take their medication. The reasons for seclusion reported by patients were mostly comparable to those given by staff. However, minor boundary violations such as swearing were also thought by some patients to lead to seclusion. Patients reported that 'acting crazy', embarrassing or tormenting staff, smoking cigarettes or throwing things might lead to seclusion. Not surprisingly, patients report feeling angry, upset or disgusted, lonely, abandoned, neglected or isolated and sad, depressed or scared during seclusion.

The review found 15 intervention studies aimed at reducing seclusion rates. Only the refurbishment of the ward environment, improved staffing levels and improved communication were show to reduce seclusion rates.

Article 3 of the European Convention on Human Rights is the right to be free from torture and cruel, inhuman or degrading treatment. Consequently, anyone subject to seclusion in a hospital in a country that is a member state of the Council of Europe must now be detained under the relevant national legislation for detention on grounds of mental illness, and seclusion must be the only reasonable option. Furthermore, 'There must be clear benefit to the individual for whom seclusion is being considered' (Mental Welfare Commission for Scotland 2014: p. 11). However, 'Where staff are in the unobstructed physical presence of the individual being supervised, then the nature of the relationship and restriction is different from seclusion because of the presence of direct human contact' (Mental Welfare Commission for Scotland 2014: p. 12). Hence, as seclusion is becoming increasingly controversial and subject to legal challenge, the simple expedient of having a member of staff present in the same room would be sufficient to avoid any claim based on the idea that seclusion was an abuse of human rights.

\section{Covert medication}

Covert medication is the administration of any medical treatment in disguised form, usually concealed in food and drink (Mental Welfare Commission for Scotland 2006). Consequently, the person is unknowingly taking medication for either a physical or mental disorder. To justify the use of covert medication, the patient must lack mental capacity - that is, they must be unable to make their own rational decisions. Capacity is now formally assessed before covert medication is administered. However, the various statutory Acts seldom mention covert medication, and this practice is often authorised (if it is authorised at all) by local policies or guidance from professional organisations. There is therefore an unclear boundary between covert medication and assault. Research has reported that over $70 \%$ of care establishments for people with dementia have used covert medication at some time (Treloar 2000). According to the current principles of informed consent, no randomised trials or prospective research can involve covert medication.

As with other forms of compulsory treatment, covert medication must be of benefit to the individual and it must also be the least restrictive option. However, one of the main safeguards for any form of involuntary restriction is the right of an individual to appeal (e.g. to the Sheriff in Scotland). This is clearly impossible if the person is unaware that they are receiving covert medication. This is particularly relevant in the event that the person recovers from an acute psychiatric disturbance and discovers that they were covertly medicated. One defence would be to demonstrate clearly that other forms of administration would have required restraint and/or force for that particular individual. Similarly, covert medication should only take place after consultation with an independent advocate, or a family and welfare guardian. The current guidance from Scotland regarding covert medication suggests weekly reviews (Mental Welfare Commission for Scotland 2006). Unfortunately, it fails to indicate that, regardless of their capacity at the time, the patient should be informed that they will be receiving covert medication (although the route of administration may be withheld). The Royal College of Psychiatrists (2004) has gone further, recommending that covert medication should only be used in people who are unable to learn and recover - such as people with severe dementia or profound intellectual disability. The College states that covert medication in schizophrenia and other severe mental illnesses, where patients can learn and understand, is 'unacceptable'.

For more information on covert medication, see Treloar et al (2000) and Ramsay (2001).

\section{References}

Amato L, Minozzi S, Davoli M, et al (2011) Psychosocial and pharmacological treatments versus pharmacological treatments for opioid detoxification. Cochrane Database of Systematic Reviews, 3: CD005031.

Amato L, Davoli MVS, Akli R, et al (2013) Methadone at tapered doses for the management of opioid withdrawal. Cochrane Database of Systematic Reviews, 2: CD003409

Angold A, Erkanli A, Egger HL, et al (2000) Stimulant treatment for children: a community perspective. Journal of the American Academy of Child and Adolescent Psychiatry, 39: 975-84.

Banaschewski T, Coghill D, Santosh P, et al (2006) Long-acting medications for the hyperkinetic disorders. A systematic review and European treatment guideline. European Child \& Adolescent Psychiatry, 15: 476-95.

Barraclough BM, Mitchell-Heggs NA (1978) Use of neurosurgery for psychological disorder in British Isles during 1974-6. BMJ, 2: 1591-3. 
BBC (2009) Cannabis row drugs adviser sacked. BBC News, 30 October (http://news.bbc.co.uk/1/hi/8334774.stm). Accessed 6 Sept 2016

Berrios GE (1997) The origins of psychosurgery: Shaw, Burckhardt and Moniz. History of Psychiatry, 8: 61-81.

Bridges PK, Bartlett JR, Hale AS, et al (1994) Psychosurgery: stereotactic subcaudate tractotomy an indispensable treatment. British Journal of Psychiatry, 165: 599-611.

Byford S, Barrett B, Metrebian N, et al (2013) Cost-effectiveness of injectable opioid treatment $v$. oral methadone for chronic heroin addiction. British Journal of Psychiatry, 203: 341-9.

Clinical Research Centre, Division of Psychiatry (1984) The Northwick Park ECT trial. Predictors of response to real and simulated ECT. British Journal of Psychiatry, 144: 227-37.

Crossley D (1993) The introduction of leucotomy: a British case history. History of Psychiatry, 4: 553-64.

Department of Health (2003) Electro Convulsive Therapy: Survey Covering the Period from January 2002 to March 2002, England (Bulletin 2003/08). Department of Health.

Department of Health (2015) Mental Health Act 1983: Code of Practice. TSO (The Stationery Office)

Gossop M, Marsden J, Stewart D (2003) The National Treatment Outcome Research Study (NTORS): 4-5 year follow-up results. Addiction, 98: 291-303.

Gregory S, Shawcross CR, Gill D (1985) The Nottingham ECT study. A double-blind comparison of bilateral, unilateral, and simulated ECT in depressive illness. British Journal of Psychiatry, 146: 520-4.

Haldeman D (1991) Sexual orientation conversion therapy for gay men and lesbians: a scientific examination. In Homosexuality: Research Implications for Public Policy (eds J Gonsiorek, J Weinrich): 149-60. Sage.

Heller AC, Amar AP, Liu CY, et al (2006) Surgery of the mind and mood: a mosaic of issues in time and evolution. Neurosurgery, 59: 720-33.

Higgins ST, Wong CJ, Badger GJ, et al (2000) Contingent reinforcement increases cocaine abstinence during out-patient treatment and 1 year follow-up. Journal of Consulting and Clinical Psychology, 68: 64-72.

HM Government (2010) Drug Strategy 2010. Reducing Demand, Restricting Supply, Building Recovery: Supporting People to Live a Drug Free Life. Home Office.

Home Affairs Select Committee (2002) Drugs: Breaking the Cycle. Written evidence submitted by Charlie Lloyd and Neil Hunt (DP156). House of Commons (http://www.publications.parliament.uk/pa/cm201213/ cmselect/cmhaff/184/184we134.htm). Accessed 23 December 2016.

Home Office (2003) The impact of Drug Treatment and Testing Orders on Offending: Two-Year Reconviction Results (Home Office Report 184). Home Office.

Hough M, Clancy A, McSweeney, et al (2003) Impact of Drug Treatment and Testing Orders on Offending: Two-Year Reconviction Results. Home Office.

Independent Working Group on Drug Consumption Rooms (2006) Drug Consumption Rooms - Summary Report of the Independent Working Group. Joseph Rowntree Foundation.

Ingram A, Saling MM, Schweitzer I (2008) Cognitive side effects of brief pulse electroconvulsive therapy: a review. Journal of ECT, 24: 3-9.

Johnstone A (2005) The Decision of the House of Lords in Munjaz (Mental Health Law Briefing 94). RadcliffesLeBrasseur.

Kaplan SL (2011) Child bipolar disorder imperiled by conflict of interest: will the credibility of child bipolar disorder be undermined? Psychology Today, 11 July (blog).

Kendall T (2013) Paying people with psychosis to improve adherence. BMJ, 347: 9

King S, Griffin S, Hodges Z, et al (2006) A systematic review and economic model of the effectiveness and cost-effectiveness of methylphenidate, dexamfetamine and atomoxetine for the treatment of attention deficit hyperactivity disorder in children and adolescents. Health Technology Assessment, 10: iii-iv, xiii-146.

Krafft-Ebing R (1886) Psychopathia Sexualis. Reprinted by Bloat Books, 1999.
Lewis R (2005) Walter Freeman's psychosurgery and biological psychiatry: a cautionary tale. Neurology Today, 5 (4): 70-2.

Lisanby SH, Maddox JH, Prudic J, et al (2000) The effects of electroconvulsive therapy on memory of autobiographical and public events. Archives of General Psychiatry, 57: 581-90.

Mashour GA, Walker EE, Martuza RL (2005) Psychosurgery: past, present and future. Brain Research Reviews, 48: 409-19.

Matthews K, Eljamel MS (2003) Status of neurosurgery for mental disorder in Scotland: selective literature review and overview of current clinical activity. British Journal of Psychiatry, 182: 404-11.

McCarthy S, Wilton L, Murray ML, et al (2012) The epidemiology of pharmacologically treated attention deficit hyperactivity disorder (ADHD) in children, adolescents and adults in UK primary care. BMC Pediatrics, 12: 78.

Mental Health Act Commission (2008) Twelfth Biennial Report. TSO (The Stationery Office).

Mental Welfare Commission for Scotland (2006) Covert Medication. Legal and Practical Guidance. Mental Welfare Commission for Scotland.

Mental Welfare Commission for Scotland (2014) Good Practice Guide: The Use of Seclusion. Mental Welfare Commission for Scotland.

Michelson D, Allen AJ, Busner J, et al (2002) Once-daily atomoxetine treatment for children and adolescents with attention deficit hyperactivity disorder: a randomized, placebo-controlled study. American Journal of Psychiatry, 159: 1896-901.

Mind (2015) Making Sense of Neurosurgery for Mental Disorder. Mind (http://www.mind.org.uk/media/2186939/making-sense-of-nmd-2015.pdf).

Molina BS, Hinshaw SP, Swanson JM, et al (2009) The MTA at 8 years: prospective follow-up of children treated for combined-type ADHD in a multisite study. Journal of the American Academy of Child and Adolescent Psychiatry, 48: 484-500.

Moncrieff J, Timimi S (2013) The social and cultural construction of psychiatric knowledge: an analysis of NICE guidelines on depression and ADHD. Anthropology \& Medicine, 20: 59-71.

Monynihan R (2011) A new deal on disease definition. BMJ, 342: d2548.

National Audit Office (2004) The Drug Treatment and Testing Order: Early Lessons (HCC 366). NAO

National Centre in HIV Epidemiology and Clinical Research (2009) Return on Investment 2: Evaluating the Cost-Effectiveness of Needle and Syringe Programs in Australia 2009. Australian Government.

National Consensus Development Panel on Effective Medical Treatment of Opiate Addiction (1998) Effective medical treatment of opiate addiction. JAMA, 280: 1936-43.

National Records of Scotland (2016) Drug Related Deaths in Scotland 2015. National Records of Scotland (https://www.nrscotland.gov.uk/ news/2016/drug-related-deaths-in-scotland-in-2015). Accessed 23 December 2016

National Treatment Agency for Substance Misuse (2012) Medications in Recovery: Re-Orientating Drug Dependence Treatment for Substance Misuse. NTA

NICE (2003) Electroconvulsive Therapy (ECT): The Clinical Effectiveness and Cost Effectiveness of Electroconvulsive Therapy (ECT) for Depressive Illness, Schizophrenia, Catatonia and Mania (TA59; modified 2009). National Institute for Health and Care Excellence.

NICE (2007) Drug Misuse in Over 16s: Psychosocial Interventions (CG51). National Institute for Health and Care Excellence.

NICE (2008) Attention Deficit Hyperactivity Disorder: Diagnosis and Management of ADHD in Children, Young People and Adults (CG72: modified 2013). National Institute for Health and Care Excellence.

NICE (2009) Depression: The Treatment and Management of Depression in Adults (CG90). National Institute for Health and Care Excellence.

NICE (2016) Attention Deficit Hyperactivity Disorder: Diagnosis and Management - Updated 2016 (CG72). National Institute for Health and Care Excellence.

Norcross JC, Koocher GP, Garofalo A (2006) Discredited psychological treatments and tests: a Delphi poll. Professional Psychology: Research and Practice, 37: 515-22. 


\section{MCQ answers}

$\begin{array}{lllll}1 b & 2 b & 3 c & 4 d & 5 a\end{array}$
Nosyk B, Sun H, Evans E, et al (2012) Defining dosing pattern characteristics of successful tapers following methadone maintenance treatment: results from a population-based retrospective cohort study. Addiction, 107: $1621-9$

Petry NM, Martin B (2002) Low-cost contingency management for treating cocaine- and opioid-abusing methadone patients. Journal of Consulting and Clinical Psychology, 70: 398-405.

Pliszka S, AACAP Work Group on Quality Issues (2007) Practice parameter for the assessment and treatment of children and adolescents with attention-deficit/hyperactivity disorder. Journal of the American Academy of Child and Adolescent Psychiatry, 46: 894-921.

Ramsay S (2001) UK nurses receive guidance on covert medication of patients. Lancet, 358: 900

Rasmussen KG (2009) Sham electroconvulsive therapy studies in depressive illness: a review of the literature and consideration of the placebo phenomenon in electroconvulsive therapy practice. Journal of ECT 25: 54-9

Reed J (2013) Why are we still using electroconvulsive therapy? BBC News (http://www.bbc.co.uk/news/health-23414888). Accessed 14 April 2016

Riddle MA, Yershova K, Lazzaretto D, et al (2013) The Preschool Attention-Deficit/Hyperactivity Disorder Treatment Study (PATS) 6-year follow-up. Journal of the American Academy of Child and Adolescent Psychiatry, 52: 264-78.e2.

Rose D, Fleischmann P, Wykes T, et al (2003) Patients' perspectives on electroconvulsive therapy: systematic review. BMJ, 326: 1363

Royal College of Psychiatrists (2000) Neurosurgery for Mental Disorder (Council Report CR89). Royal College of Psychiatrists

Royal College of Psychiatrists (2004) College statement on covert administration of medicines. Psychiatric Bulletin, 28: 385-6.

Russell G, Rodgers LR, Ukoumunne OC, et al (2014) Prevalence of parentreported ASD and ADHD in the UK: findings from the Millennium Cohort Study. Journal of Autism and Developmental Disorders, 44: 31-40.

Satcher D (2001) The Surgeon General's Call to Action to Promote Sexual Health and Responsible Sexual Behavior. Office of the Surgeon General

Sees KL, Delucchi KL, Masson C, et al (2000) Methadone maintenance vs 180-day psychosocially enriched detoxification for treatment of opioid dependence: a randomized controlled trial. JAMA, 283: 1303-10.

Simpson DD, Joe GW, Rowan-Szal GA (1997) Drug abuse treatment retention and process effects on follow-up outcomes. Drug and Alcohol Dependence, 47: 227-35.
Sonuga-Barke EJ, Brandeis D, Cortese S, et al (2013) Nonpharmacological interventions for ADHD: systematic review and meta-analyses of randomized controlled trials of dietary and psychological treatments. American Journal of Psychiatry, 170: 275-89.

Strang J, Metrebian N, Lintzeris N, et al (2010) Supervised injectable heroin or injectable methadone versus optimised oral methadone as treatment for chronic heroin addicts in England after persistent failure in orthodox treatment (RIOTT): a randomised trial. Lancet, 375: 1885-95.

Strohl MP (2011) Bradley's benzedrine studies on children with behavioral disorders. Yale Journal of Biology and Medicine, 84: 27-33.

Swayze VW (1995) Frontal leukotomy and related psychosurgical procedures in the era before antipsychotics (1935-1954): a historical overview. American Journal of Psychiatry, 152: 505-15.

Treloar A, Beats B, Philpot M (2000) A pill in the sandwich: covert medication in food and drink. Journal of the Royal Society of Medicine, 93: 408-11.

Turnbull PJ, McSweeney T, Webster R (2000) Drug Treatment and Testing Orders: Final Evaluation Report. Home Office Research, Development and Statistics Directorate.

UK ECT Review Group (2003) Efficacy and safety of electroconvulsive therapy in depressive disorders: a systematic review and meta-analysis. Lancet, 361: 799-808.

Van der Merwe M, Bowers L, Jones J, et al (2009) Sec/usion: A Literature Review. City University (http://www.kcl.ac.uk/ioppn/depts/hspr/ research/ciemh/mhn/projects/litreview/LitRevSeclusion.pdf)

Verkuijl N, Perkins M, Fazel M (2015) Childhood attention-deficit/ hyperactivity disorder. BMJ, 350: h2168.

Visser SN, Danielson ML, Bitsko RH, et al (2014) Trends in the parentreport of health care provider-diagnosed and medicated attentiondeficit/hyperactivity disorder: United States, 2003-2011. Journal of the American Academy of Child and Adolescent Psychiatry, 53: 34-46.

Young S, Amarasinghe JM (2010) Practitioner review: nonpharmacological treatments for ADHD: a lifespan approach. Journal of Child Psychology and Psychiatry, 51: 116-33.

Ward J, Hall W, Mattick RP (1999) Role of maintenance treatment in opioid dependence. Lancet, 353: 221-6.

Wodak A, Cooney A (2004) Effectiveness of Sterile Needle and Syringe Programming in Reducing HIV/AIDS among Injecting Drug Users. World Health Organization.

Wright NM, Tompkins CN (2004) Supervised injecting centres. BMJ, 328: $100-2$.

Yoshino K (2002) Covering. Yale Law Journal, 111: 769.

\section{MCQs}

Select the single best option for each question stem

1 A famous author who killed himself shortly after treatment with ECT was:

a Lord Byron

b Ernest Hemingway

c Joe Orton

d John Steinbeck

e Tennessee Williams.

2 The number of psychosurgery procedures performed in the UK in 2013-2014 was:

a 1 or 2

b 4 or 5

c 20 to 30

d 100 to 200

e 150 to 250 .
3 A reasonable estimate of the effect size of methylphenidate for treatment of childhood ADHD is:

a 0.2

b 0.5

c 1

d 2

e 4 .

4 A substance misuse treatment that has been expanded in the UK despite equivocal results from research trials is:

a injectable opioid therapy

b methadone maintenance

c drug consumption rooms

d drug treatment testing orders

e residential rehabilitation.
5 Seclusion:

a does not occur if a member of staff is in the same room as the patient

b can be justified if staffing numbers are inadequate

c may be used to prevent self-harm

d may be deployed for patients who are not detained under the Mental Health Act

e is most commonly used because of refusal to take medication. 